\title{
Reliability and known-group validity of the Arabic version of the 8-item Morisky Medication Adherence Scale among type 2 diabetes mellitus patients
}

\author{
S.T. Ashur, ${ }^{1}$ K. Shamsuddin, ${ }^{1}$ S.A. Shah, ${ }^{1}$ S. Bosseri ${ }^{2}$ and D.E. Morisky ${ }^{3}$
}

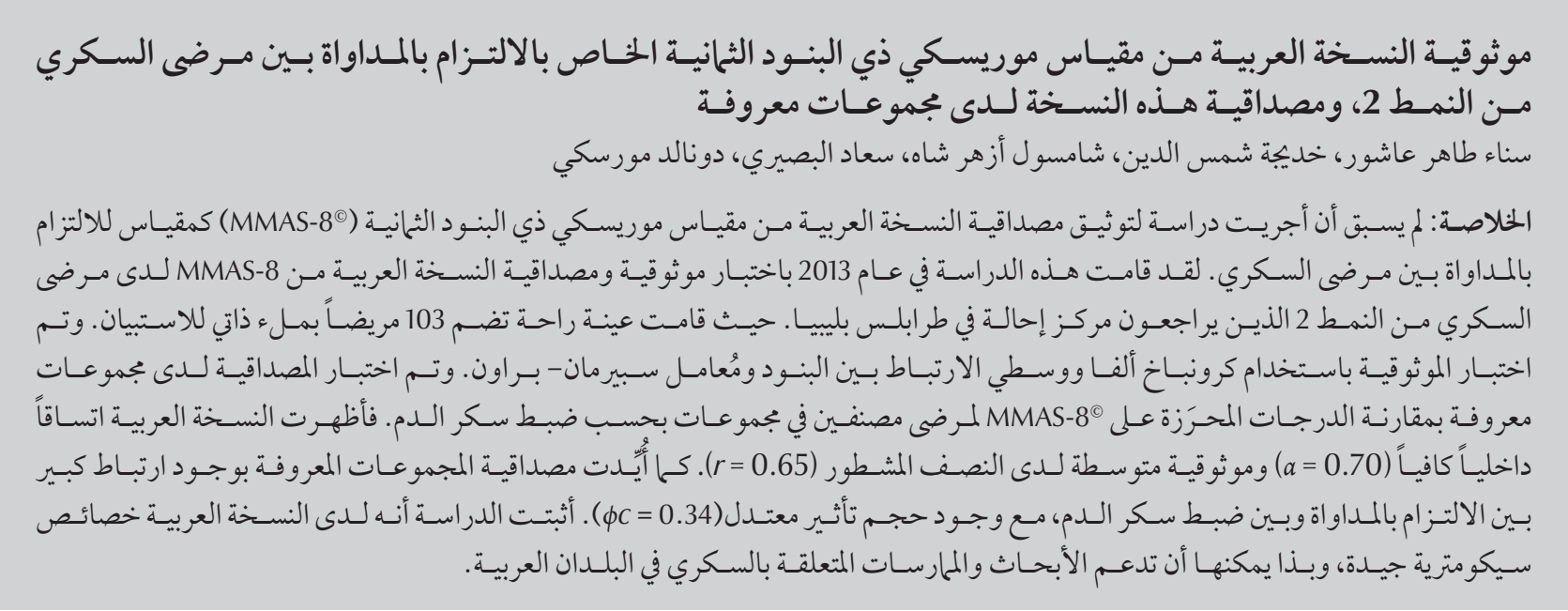

ABSTRACT No validation study has previously been made for the Arabic version of the 8-item Morisky Medication Adherence Scale $\left(\mathrm{MMAS}^{\circ} \mathrm{8}^{\circ}\right.$ ) as a measure for medication adherence in diabetes. This study in 2013 tested the reliability and validity of the Arabic MMAS-8 for type 2 diabetes mellitus patients attending a referral centre in Tripoli, Libya. A convenience sample of 103 patients self-completed the questionnaire. Reliability was tested using Cronbach alpha, average inter-item correlation and Spearman-Brown coefficient. Known-group validity was tested by comparing MMAS-8 scores of patients grouped by glycaemic control. The Arabic version showed adequate internal consistency $(\alpha=0.70)$ and moderate split-half reliability $(r=0.65)$. Known-group validity was supported as a significant association was found between medication adherence and glycaemic control, with a moderate effect size $(\phi c=0.34)$. The Arabic version displayed good psychometric properties and could support diabetes research and practice in Arab countries.

Fiabilité et validité par groupe connu de la version en langue arabe du questionnaire de Morisky à 8 items sur l'adhésion au traitement chez des patients atteints de diabète de type 2

RÉSUMÉ Aucune étude de validation n'a été menée pour la version en langue arabe du questionnaire de Morisky à 8 items (Morisky Medication Adherence Scale - MMAS-8 ${ }^{\odot}$ ) visant à mesurer l'adhésion au traitement du diabète. La présente étude menée en 2013 a testé la fiabilité et la validité de la version en langue arabe de l'échelle MMAS-8 chez des patients atteints de diabète de type 2 consultant dans une clinique de recours à Tripoli (Libye). Dans un échantillon de proximité, 103 patients ont rempli l'autoquestionnaire. La fiabilité a été testée à l'aide de l'alpha de Cronbach, de la corrélation moyenne entre item et du coefficient de Spearman-Brown. La validité par groupe connu a été testée en comparant les scores MMAS-8 des patients regroupés par contrôle glycémique. La version en langue arabe a révélé une cohérence interne adéquate $(\alpha=0,70)$ et une fiabilité fractionnée modérée $(r=0,65)$. La validité par groupe connu a été confirmée par une association significative observée entre l'adhésion au traitement et le contrôle de la glycémie, avec une taille d'effet modérée $(\phi c=0,34)$. La version en langue arabe avait des propriétés psychométriques satisfaisantes et pourrait être utile pour la recherche sur le diabète et la pratique y afférente dans les pays arabes.

'Department of Community Health, Universiti Kebangsaan Malaysia Medical Centre, Kuala Lumpur, Malaysia (Correspondence to S. T. Ashur: drsana04@yahoo.com). ${ }^{2}$ National Centre for Diabetes and Endocrinology, Tripoli, Libya. ${ }^{3}$ Department of Community Health Sciences, UCLA Fielding School of Public Health, Los Angles, California, United States of America.

Received: 23/02/15; accepted: 29/07/15 


\section{Introduction}

Adherence to diabetes medications is essential for achieving better glycaemic control in patients with diabetes mellitus (1-3). Poor adherence has been associated with higher health-care expenditure (4) and so medication adherence is also important to reduce disease-related costs (5). Low adherence to diabetes medication is a particular concern in countries where the burden of diabetes is high, as in the case with many Arab nations. According to the International Diabetes Federation, the Middle East and North Africa, which is mostly comprises Arab countries, has the highest comparative prevalence of diabetes among adults compared with other regions (6). It is important therefore to have a valid measure of medication adherence that can be used in Arabic-language clinical settings in order to be able to assess which patients are poor adherers.

Several tools are available for measuring medication adherence. Among these are blood assay, electronic monitoring of medications containers, pill counts and self-reporting methods $(7,8)$. The selection of any of these measures is determined by several factors. Some tools, such as blood assay, could be of limited utility, as they cannot be used for all medications (8). Moreover, otherissues, such asfeasibility and cost, could preclude the use of many sophisticated medication adherence measuring methods, such as blood assay and electronic monitoring (8). This is especially a concern in settings where such methods are unavailable, which is the case in many clinical facilities of several Arab countries. On the other hand, self-reporting measures are easy to use and affordable and they have been recommended for use in clinics (8). Nevertheless, among the available self-reporting measures, simplicity is an essential element to consider when choosing a self-reporting measure, especially in some studies and in busy clinics (9).

Among the simple and the most commonly used self-reporting medication adherence measures is the 8-item Morisky Medication Adherence Scale (MMAS- $\left.8^{\odot}\right)$ (10). This scale and was developed from the 4-item Morisky Medication Adherence Scale (MMAS4) (11) and the Morisky, Green, Levine Adherence Scale (12). The original English-language MMAS-8 is a reliable and valid tool, and its psychometric assessments included testing for its reliability, concurrent and predictive validity (10) and its concordance with pharmacy dispensing data (13). It displayed satisfactory internal consistency reliability, with a Cronbach alpha coefficient of 0.83 (10). The original MMAS- 8 showed a significant correlation with the original MMAS-4, which supports its concurrent validity, and its predictive validity was supported by testing the association between medication adherence as measured by the scale and several medication adherence-related criteria (10). The single dimension structure of the original MMAS-8 was supported using factor analysis, whereby all of its items loaded on 1 component, with a minimum factor loading of 0.425 (10). In addition, the concurrent and concordance validity of the original MMAS-8 were supported using pharmacy refill medication adherence data (13).

The MMAS- 8 has been used widely for several different diseases — including diabetes $(1,14,15)$, schizophrenia (16) and epilepsy $(17,18)$-and among different cultural groups. Several versions of the scale in different languages have been psychometrically evaluated, for example the Turkish (19), Urdu (20), Malaysian (21), Korean (22), Portuguese (23) and French (24) versions. All of these translated versions showed acceptable levels of reliability and validity. The scale has also been used among Arab populations for several disease groups. An Arabic version of the MMAS- 8 was used in Palestine to measure adherence to medication for diabetes $(14,15)$ and epilepsy (17), and in Egypt to assess adherence to schizophrenia medication (16). More recently, the scale was used to assess medication adherence among a sample of patients with a mix of chronic diseases in Saudi Arabia (25). However, we could not locate any published validation study of the Arabic version of the MMAS-8 within an Arab population with type 2 diabetes.

This pilot study aimed to test the reliability and known-group validity of the Arabic version of the MMAS-8 specifically as a measure for diabetes medication adherence among type 2 diabetes mellitus patients in clinical settings.

\section{Methods}

\section{Study design and settings}

A pilot study was conducted between August and October 2013 in the National Centre for Diabetes and Endocrinology, Tripoli, Libya. The study was approved by the institutional medical ethics committee at Universiti Kebangsaan Malaysia Medical Centre, Kuala Lumpur, Malaysia, and the authorities in the Centre.

\section{Sampling}

There is no universal recommendation for an ideal number of subjects to be recruited in pilotstudies. Asample size of 100 or less could be considered in such studies (26). Accordingly, the sample size was set at 100 with an assumption of $25 \%$ non-response. Therefore, the target sample size for this study was 125 respondents.

A total of 125 patients were recruited consecutively by the investigator in the waiting area of the outpatient clinics. The eligibility criteria included being Libyan, aged 18 years and above, having type 2 diabetes mellitus for at least 1 year, being on diabetes medications rather than 
diet control alone, able to read and write in Arabic, having no visual or cognitive impairment that interfered with the ability to independently complete the questionnaire, and willing to participate in the study. Pregnant diabetic women were also excluded because they are under a special management in terms of both medication and follow-up protocol. Very ill patients were also not eligible.

Prior to recruitment, a verbal briefing on the study was provided to all potential respondents and an information sheet was given to those who agreed to participate in the study. Participation in the study was voluntary and signed consent was obtained from each patient.

\section{Measures}

The respondents completed a selfadministered questionnaire that included 3 sections: sociodemographic data (age, sex, marital status, education level and employment status); disease profile (duration of diabetes, current diabetes medications and the most recent glycosylated haemoglobin (HbAlc) result, i.e. not older than 3 months); and the Arabic version of the MMAS-8. The self-reported HbAlc value was verified by the investigator who checked the follow-up records and the latest laboratory results brought by the respondent for the follow-up visit before the final collection of the questionnaires. To reduce the number of incomplete questionnaires, the investigator checked them before final collection.

The MMAS- 8 scale consists of 8 items. Each of the first 7 items has 2 possible responses (yes/no), while the 8thitemis answered witha 5-point Likert scale. The possible total medication adherence score ranges between 0 and 8 , and the higher the score, the better the adherence level. A total score $<6$ is considered low adherence, while a total score of $\geq 6$ but $<8$ indicates moderate adherence, and a score of 8 indicates high adherence.

The Arabic version of the MMAS8 scale was obtained with permission from the scale owner. This version was developed using a strict forward and backward translation protocol, whereby 2 pairs of linguistic experts performed the translation independently. The version is in modern standard Arabic language, which is the language used for reading and writing in Arab countries, including Libya.

\section{Validation of the scale}

\section{Reliability assessment}

Internal consistency reliability was tested using the Cronbach alpha coefficient, along with the corrected item total correlation. However, as alpha is sensitive to the number of items, a low alpha is frequently reported for short scales (27). Therefore, other consistency reliability statistics that were recommended as more appropriate for scales with few items were also assessed. These were the average interitem correlation (27), and the split-half reliability using the Spearman-Brown coefficient; the latter was recommended as the most appropriate reliability measure for 2-item measures (28).

\section{Known-group validity}

To examine the known-group validity of the questionnaire, the association between glycaemic control status and medication adherence as measured by the Arabic version of the MMAS- 8 was tested using Pearson chi-squared test. The respondents were categorized into 3 medication adherence groups based on their total scores: low (score $<6$ ), moderate (score $\geq 6-<8$ ) and high adherers (score 8). Patients were categorized into 2 glycaemic control groups based on the American Diabetes Association recommendations of $<7 \%$ for the target HbAlc level (29): good control $(\mathrm{HbAlc}<7 \%)$ and poor control ( $\mathrm{HbAlc} \geq 7 \%)$. As a $2 \times 3$ contiguous table was used, Cramer V statistic $(\phi c)$ was used to quantify the effect size (30) of the association between medication adherence and glycaemic control.

\section{Diagnostic accuracy}

The sensitivity and specificity and positive predictive value and negative predictive value of the Arabic version were assessed when the total MMAS-8 score of 6 was used as a cut-off point for dichotomizing patients into low and moderate-to-high adherers, as per the scale instructions.

\section{Statistical analysis}

SPSS, version 22, was used to conduct the data analysis. Data cleaning and the required item reversing and standardization, as depicted in the MMAS-8 scoring instructions were carried out before proceeding to the main analysis. The $95 \%$ confidence intervals (CI) for sensitivity, specificity, positive predictive value and negative predictive value were computed using the DAG-Stat spreadsheet (31)

\section{Results}

\section{Sample characteristics}

Of the 125 distributed questionnaires, only 103 useable questionnaires were returned and were considered for the analysis, which gave the study a response rate of $82.4 \%$. Both sexes were represented, with females comprising $68.9 \%$ of the sample. The mean age of the respondents was 52.7 (SD 8.6) years, and $80.6 \%$ of them were married. Out of all the respondents, $55.3 \%$ had primary education and $53.4 \%$ were housewives. The disease profile questions revealed that $32.0 \%$ of respondents had had diabetes for more than 10 years and $47.6 \%$ of them were on both oral hypoglycaemic agents plus insulin. The mean HbAlc level was 9.10\% (SD 2.31\%). Mean total medication adherence score was 5.25 (SD 2.01), and $56.3 \%$ of the respondents were low adherers (Table 1). 


\section{Reliability assessment}

The reliability of the Arabic version of the MMAS-8 was assessed using Cronbach alpha coefficient, average interitem correlation and Spearman-Brown coefficient. The Arabic MMAS-8 version showed adequate internal consistency reliability $(\alpha=0.70)$. All the corrected item total correlations were optimal (0.34-0.51), except for item 5; this item showed the lowest corrected item total correlation $(r=0.25)$. However, deleting this item did not appreciably improve the alpha value $(\alpha=0.71)$ and so the item was retained. The version also displayed optimal average inter-item correlation $(r=0.25)$ and a moderate split-half reliability as indicated by the SpearmanBrown coefficient $(r=0.65)$ (Table 2).

\section{Known-group validity}

Known-group validity was assessed by comparing the MMAS- 8 scores of patients grouped by glycaemic control

\begin{tabular}{|c|c|c|}
\hline \multicolumn{3}{|c|}{$\begin{array}{l}\text { Table } 1 \text { Sociodemographic characteristics, diabetes profile and medication } \\
\text { adherence of patients with diabetes }(n=103) \text { based on the } 8 \text {-item Morisky } \\
\text { Medication Adherence Scale }\end{array}$} \\
\hline Variable & \multicolumn{2}{|c|}{ Value } \\
\hline Age (years) [mean $(S D)]$ & \multicolumn{2}{|c|}{$52.7(8.6)$} \\
\hline \multicolumn{3}{|l|}{$\operatorname{Sex}($ no., \%) } \\
\hline Female & 71 & 68.9 \\
\hline Male & 32 & 31.1 \\
\hline \multicolumn{3}{|l|}{ Marital status (no., \%) } \\
\hline Single & 2 & 1.9 \\
\hline Married & 83 & 80.6 \\
\hline Divorced & 4 & 3.9 \\
\hline Widowed & 14 & 13.6 \\
\hline \multicolumn{3}{|l|}{ Education level (no., \%) } \\
\hline Primary & 57 & 55.3 \\
\hline Secondary & 32 & 31.1 \\
\hline University/higher education & 14 & 13.6 \\
\hline \multicolumn{3}{|l|}{ Employment status (no., \%) } \\
\hline Employed & 36 & 35.0 \\
\hline Unemployed & 12 & 11.7 \\
\hline Housewife & 55 & 53.4 \\
\hline \multicolumn{3}{|l|}{ Diabetes duration (years) (no., \%) } \\
\hline$<5$ & 38 & 36.9 \\
\hline $5-10$ & 32 & 31.1 \\
\hline$>10$ & 33 & 32.0 \\
\hline \multicolumn{3}{|l|}{ Diabetes medication (no., \%) } \\
\hline Oral hypoglycaemic & 31 & 30.1 \\
\hline Insulin & 23 & 22.3 \\
\hline Oral hypoglycaemic + insulin & 49 & 47.6 \\
\hline HbA1c (\%) [mean (SD)] & \multicolumn{2}{|c|}{$9.10(2.31)$} \\
\hline Overall MMAS-8 score [mean (SD)] & \multicolumn{2}{|c|}{$5.25(2.01)$} \\
\hline \multicolumn{3}{|l|}{ Medication adherence groups (No., \%) } \\
\hline Low $($ score $<6)$ & 58 & 56.3 \\
\hline Moderate (score $\geq 6-<8$ ) & 35 & 34.0 \\
\hline High (score 8) & 10 & 9.7 \\
\hline
\end{tabular}

$S D=$ standard deviation; HbA7c = glycosylated haemoglobin . status using the Pearson chi-squared test. Among 58 patients who were selfreported low adherers to medication, 55 (94.8\%) had poorly controlled diabetes. The association between medication adherence and glycaemic control was found to be statistically significant $\left(\chi^{2}\right.$ $=12.38, P=0.002)$. The effect size was moderate $(\phi c=0.34)$, and these findings support the known-group validity of the Arabic version MMAS-8 (Table 3).

\section{Diagnostic accuracy}

The sensitivity, specificity, positive predictive value and negative predictive value of the Arabic MMAS- 8 were assessed with patients dichotomized into low and moderate-high adherers at the cut-off score of 6 . At this cutoff, the Arabic version MMAS-8 had sensitivity of $63.9 \%$ (95\% CI: $52.8-$ $74.0 \%$ ), specificity of $82.3 \%$ (95\% CI: 56.5-96.2\%), positive predictive value of $94.8 \%$ (95\% CI: $85.6-98.9 \%)$ and negative predictive value of $31.1 \%$ (95\% CI: 18.1-46.6\%) (Table 4).

\section{Discussion}

The findings obtained from this study support the Arabic version of MMAS8 as a reliable and valid measure for medication adherence in diabetes. All reliability measures were acceptable. The reported alpha coefficient was adequate and indeed was highly satisfactory when considering the sensitivity of the alpha statistic to thelength of the scale (27). The alpha coefficient reported in this study is lower than that reported for the scale among a patients with a mix of different chronic diseases in a Saudi Arabian study (0.795) (25). Compared with other translated versions of the MMAS8 that were evaluated as measures for medication adherence in diabetes, the reported alpha value in this study was higher than those reported for the Malaysian (0.657) (21), Korean (0.66) (22) and Thai (0.61) (32) versions. However, the alpha coefficient for the 


\begin{tabular}{|c|c|c|c|c|}
\hline \multicolumn{5}{|c|}{$\begin{array}{l}\text { Table } 2 \text { Reliability of the Arabic version of } 8 \text {-item Morisky Medication Adherence } \\
\text { Scale among patients with type } 2 \text { diabetes mellitus }(n=103) \text { in clinical settings in } \\
\text { Libya }\end{array}$} \\
\hline $\begin{array}{l}\text { Scale } \\
\text { items }\end{array}$ & $\begin{array}{l}\text { Corrected item } \\
\text { total correlation } \\
(r)\end{array}$ & $\begin{array}{l}\text { Cronbach } \\
\text { alpha } \\
(\alpha)\end{array}$ & $\begin{array}{l}\text { Average inter-item } \\
\text { correlation } \\
(r)\end{array}$ & $\begin{array}{l}\text { Spearman-Brown } \\
\text { correlation } \\
(r)\end{array}$ \\
\hline 1 & 0.345 & - & - & - \\
\hline 2 & 0.463 & - & - & - \\
\hline 3 & 0.510 & - & - & - \\
\hline 4 & 0.414 & - & - & - \\
\hline 5 & $0.253^{\mathrm{a}}$ & $0.71^{b}$ & - & - \\
\hline 6 & 0.465 & - & - & - \\
\hline 7 & 0.401 & - & - & - \\
\hline 8 & 0.488 & - & - & - \\
\hline $1-8$ & $0.253-0.510$ & 0.70 & 0.25 & 0.65 \\
\hline
\end{tabular}

${ }^{a}$ Item with the least corrected item total correlation; ${ }^{b}$ if item 5 was deleted.

Arabic version in the current study was lower than that reported for the original scale among patients diagnosed with hypertension (0.83) (10). The Arabic version displayed an average inter-item correlation that falls within the optimal range (33), which reflects an adequate homogeneity of the items. Additionally, the Spearman-Brown coefficient result indicated moderate split-half reliability. Furthermore, all the items showed optimal corrected item total correlations except for item 5. This item asks if the respondent took the medications the day before. As this study was conducted in clinical settings, it was expected that a high proportion of the respondents would give a positive response to this item. This is because they knew in advance that they would be seen by their health-care provider on the next day and that blood tests might be requested to evaluate their blood glucose level. This might be the reason for the relatively lower corrected item total correlation observed for this item.

The Arabic version was able to differentiate between diabetic patients with poor and good glycaemic control, which is known to be affected by medication adherence. This supported the known-group validity of the version. The reported association displayed a moderate effect size. This result was satisfactory because small and modest size effects had been frequently reported for behavioural factors (34). Similarly, known-group validity in the context of diabetes was also supported for other MMAS-8 translated versions such as the Malaysian (21) and Thai (32) versions.

The Arabic version displayed a sensitivity lower than that reported with the original English-language scale among respondents with hypertension (93\%) (10).However, to some extent, the reported sensitivity was comparable to the sensitivity reported among diabetics for the same cut-off point score with the Malaysian (77.6\%) (21) and Korean (74\%) (22) versions but was higher than that reported with the Thai version (51\%) (32). The reported sensitivity reflects a reasonable ability of the Arabic version to correctly identify type 2 diabetes patients who are low adherers to their medications, and it is deemed satisfactory especially considering the simplicity of the scale as a short self-reporting measure. The reported specificity of the Arabic version among diabetes patients was higher than that reported with the original version among patients with hypertension (53\%) (10) and it was also higher than the specificity reported for diabetes patients with the Malaysian (45.37\%) (21), Korean (38.3\%) (22), and Thai (64\%) (32) versions. Moreover, our study showed that the Arabic version had a high positive predictive value at this cut-off point, but a low negative predictive value. These indices are deemed reasonable and lend support to the Arabic version as a suitable screening tool for poor medication adherence in clinical settings, especially in view of the other advantages of self-reporting, such as being easy and quick to apply, affordable and non-invasive.

This pilot study represents the first insight into the validity of the Arabic version of MMAS-8 as a measure of medication adherence in diabetes, and it provides evidence about several psychometric aspects of this selfadministered measure. As the Arab countries are facing a high burden of

\begin{tabular}{|c|c|c|c|c|c|c|c|}
\hline \multirow[t]{3}{*}{ Medication adherence group } & \multicolumn{4}{|c|}{ Glycaemic control status } & \multirow[t]{3}{*}{$x^{2}$} & \multirow[t]{3}{*}{$P$-value } & \multirow[t]{3}{*}{$\phi C$} \\
\hline & \multicolumn{2}{|c|}{$\begin{array}{c}\text { Poor } \\
(\mathrm{HbA1c} \geq 7 \%)\end{array}$} & \multicolumn{2}{|c|}{$\begin{array}{c}\text { Good } \\
(\mathrm{HbA1c}<7 \%)\end{array}$} & & & \\
\hline & No. & $\%$ & No. & $\%$ & & & \\
\hline Low adherers $($ score < 6) & 55 & 94.8 & 3 & 5.2 & 12.383 & 0.002 & 0.34 \\
\hline Moderate adherers $($ score $\leq 6-<8$ ) & 24 & 68.6 & 11 & 31.4 & & & \\
\hline High adherers (score 8) & 7 & 70.0 & 3 & 30.0 & & & \\
\hline
\end{tabular}

HbA7c = glycosylated haemoglobin. 


\begin{tabular}{|c|c|c|c|c|c|}
\hline \multirow[t]{3}{*}{ Variable } & \multicolumn{3}{|c|}{ Glycaemic control status } & \multirow{2}{*}{\multicolumn{2}{|c|}{$\begin{array}{l}\text { Diagnostic accuracy of the } \\
\text { MMAS-8 }\end{array}$}} \\
\hline & $\begin{array}{c}\text { Poor } \\
(\text { HbAlc } \geq 7 \%)\end{array}$ & $\begin{array}{c}\text { Good } \\
(\text { HbAlc }<7 \%)\end{array}$ & Total & & \\
\hline & No. & No. & No. & $\%$ & $95 \% \mathrm{Cl}$ \\
\hline \multicolumn{6}{|l|}{ Medication adherence group ${ }^{a}$} \\
\hline Low adherers (score < 6) & 55 & 3 & 58 & - & - \\
\hline Moderate-to-high adherers (score $\geq 6$ ) & 31 & 14 & 45 & - & - \\
\hline Total & 86 & 17 & 103 & - & - \\
\hline Sensitivity & - & - & - & 63.9 & $52.8-74.0$ \\
\hline Specificity & - & - & - & 82.3 & $56.5-96.2$ \\
\hline Positive predictive value & - & - & - & 94.8 & $85.6-98.9$ \\
\hline Negative predictive value & - & - & - & 31.1 & $18.1-46.6$ \\
\hline
\end{tabular}

${ }^{a}$ Medication adherence groups dichotomized at total MMAS-8 score of 6 . $\mathrm{HbA7c}=$ glycosylated haemoglobin; $\mathrm{Cl}=$ confidence interval .

type 2 diabetes mellitus, the findings have important implications for diabetes care in these settings. This measure would help in providing valid data on medication adherence levels to be used in the planning of locally appropriate strategies to handle sub-optimal adherence. Clinically, measuring medication adherence with a sound tool would also help to identify patients who are in need of intervention.

The main weaknesses of the study were related to the methodology. The small sample size used in this pilot study might have influenced the results. The non-probability sampling might impose limitations on the generalizability of the findings. However, a large number of type 2 diabetes mellitus patients from Tripoli and its surroundings are being followed up in our Centre and the sample included a diverse group of patients. In addition, the demographic profile of the respondents corresponded to the epidemiological pattern of type 2 diabetes mellitus in Libya (35) in terms of age and sex. Other possible limitations include those related to self-reporting, such as recall bias and over-reporting of medication adherence. Additionally, the interpretation of the study findings should consider that this study validated the Arabic version of the MMAS- 8 as a self-administered tool rather than as an interview tool. Therefore, patients who could not complete the version independently for reasons of illiteracy or low visual acuity might need to be considered in further research that would evaluate the version as an interview tool. Besides, the results should also be viewed with the consideration that this study was done in a clinical facility and perhaps studies in non-clinical settings would produce different findings. Another limitation of this study is that, for logistic reasons, test-retest assessment of the time stability of the version was not included.

\section{Conclusion}

The Arabic version of MMAS-8 displayed satisfactory reliability and validity as a self-administered medication adherence measure for patients with type 2 diabetes mellitus. This finding lends support to its use in clinical settings with Arab-speaking populations. Therefore, the findings are believed to have implications on research and clinical practice in several Arab countries which have been facing a high burden of diabetes mellitus, especially when other sophisticated medication adherence measures are not feasible.

\section{Acknowledgements}

Use of the MMAS ${ }^{\circ}$ is protected by United Statescopyright laws.Permission for use is required. A license agreement is available from Donald E. Morisky, Department of Community Health Sciences, UCLA School of Public Health, 650 Charles E. Young Drive South, Los Angeles, CA 90095-1772.

Funding: This study was supported by a research grant from Universiti Kebangsaan Malaysia Medical Centre under the project code FF-2013-298.

Competing interests: None declared.

\section{References}

1. Al-Qazaz HKh, Sulaiman SA, Hassali MA, Shafie AA, Sundram $\mathrm{S}$, Al-Nuri R, et al. Diabetes knowledge, medication adherence and glycemic control among patients with type 2 diabetes. Int J Clin Pharm. 2011 Dec;33(6):1028-35. PMID:22083724
2. Rozenfeld Y, Hunt JS, Plauschinat C, Wong KS. Oral antidiabetic medication adherence and glycemic control in managed care. Am J Manag Care. 2008 Feb;14(2):71-5. PMID:18269302 
3. Tiv M, Viel J-F, Mauny F, Eschwège E, Weill A, Fournier C, et al. Medication adherence in type 2 diabetes: the ENTRED study 2007, a French Population-Based Study. PLoS One. 2012;7(3):e32412. PMID:22403654

4. Wild $\mathrm{H}$. The economic rationale for adherence in the treatment of type 2 diabetes mellitus. Am J Manag Care. 2012 Apr;18(3) Suppl:S43-8. PMID:22558941

5. Sokol MC, McGuigan KA, Verbrugge RR, Epstein RS. Impact of medication adherence on hospitalization risk and healthcare cost. Med Care. 2005 Jun;43(6):521-30. PMID:15908846

6. IDF Diabetes atlas. 6th ed. Brussels: International Diabetes Federation; 2013 (https://www.idf.org/sites/default/files/ EN_6E_Atlas_Full_0.pdf, accessed 30 August 2015).

7. Farmer KC. Methods for measuring and monitoring medication regimen adherence in clinical trials and clinical practice. Clin Ther. 1999 Jun;21(6):1074-90, discussion 1073. PMID:10440628

8. Garfield S, Clifford S, Eliasson L, Barber N, Willson A. Suitability of measures of self-reported medication adherence for routine clinical use: a systematic review. BMC Med Res Methodol. 2011;11:149. PMID:22050830

9. Morisky DE, DiMatteo MR. Improving the measurement of self-reported medication nonadherence: final response. J Clin Epidemiol. 2011 Mar;64(3):255-7.

10. Morisky DE, Ang A, Krousel-Wood M, Ward HJ. Predictive validity of a medication adherence measure in an outpatient setting. J Clin Hypertens (Greenwich). 2008 May;10(5):348-54. PMID:18453793

11. Morisky DE, Malotte CK, Choi P, Davidson P, Rigler S, Sugland $\mathrm{B}$, et al. A patient education program to improve adherence rates with antituberculosis drug regimens. Health Educ Q. 1990 Fall;17(3):253-67. PMID:2228629

12. Morisky DE, Green LW, Levine DM. Concurrent and predictive validity of a self-reported measure of medication adherence. Med Care. 1986 Jan;24(1):67-74. PMID:3945130

13. Krousel-Wood M, Islam T, Webber LS, Re RN, Morisky DE, Muntner P. New medication adherence scale versus pharmacy fill rates in seniors with hypertension. Am J Manag Care. 2009 Jan;15(1):59-66. PMID:19146365

14. Jamous RM, Sweileh WM, Abu-Taha AS, Sawalha AF, Zyoud $\mathrm{SH}$, Morisky DE. Adherence and satisfaction with oral hypoglycemic medications: a pilot study in Palestine. Int J Clin Pharm. 2011 Dec;33(6):942-8. PMID:21918840

15. Sweileh WM, Zyoud SH, Abu Nab'a RJ, Deleq MI, Enaia MI, Nassar SM, et al. Influence of patients' disease knowledge and beliefs about medicines on medication adherence: findings from a cross-sectional survey among patients with type 2 diabetes mellitus in Palestine. BMC Public Health. 2014;14:94. PMID:24479638

16. Amr M, El-Mogy A, El-Masry R. Adherence in Egyptian patients with schizophrenia: the role of insight, medication beliefs and spirituality. Arab J Psychiatry. 2013;24(1):60-8.

17. Sweileh WM, Ihbesheh MS, Jarar IS, Taha AS, Sawalha AF, Zyoud $\mathrm{SH}$, et al. Self-reported medication adherence and treatment satisfaction in patients with epilepsy. Epilepsy Behav. 2011 Jul;21(3):301-5. PMID:21576040

18. Yang A, Wang B, Zhu G, Jiao Z, Fang Y, Tang F, et al. Validation of Chinese version of the Morisky medication adherence scale in patients with epilepsy. Seizure. 2014 Apr;23(4):295-9. PMID:24484672

19. Hacıhasanoğlu Aşılar R, Gözüm S, Çapık C, Morisky DE. Reliability and validity of the Turkish form of the eight-item Morisky medication adherence scale in hypertensive patients. Anadolu Kardiyol Derg. 2014 Dec;14(8):692-700. PMID:25188758

20. Saleem F, Hassali MA, Akmal S, Morisky DE, Atif M, Al-Qazaz HKh, et al. Translation and validation study of Morisky Medication Adherence scale (MMAS): the Urdu version for facilitating person-centered healthcare in Pakistan. Int J Pers Cent Med. 2012;2(3):384-90.

21. Al-Qazaz HKh, Hassali MA, Shafie AA, Sulaiman SA, Sundram S, Morisky DE. The eight-item Morisky Medication Adherence Scale MMAS: translation and validation of the Malaysian version. Diabetes Res Clin Pract. 2010 Nov;90(2):216-21. PMID:20832888

22. Lee WY, Ahn J, Kim JH, Hong YP, Hong SK, Kim YT, et al. Reliability and validity of a self-reported measure of medication adherence in patients with type 2 diabetes mellitus in Korea. J Int Med Res. 2013 Aug;41(4):1098-110. PMID:23860015

23. de Oliveira-Filho AD, Morisky DE, Neves SJ, Costa FA, de Lyra DP Jr. The 8-item Morisky Medication Adherence Scale: validation of a Brazilian-Portuguese version in hypertensive adults. Res Social Adm Pharm. 2014 May-Jun;10(3):554-61. PMID:24268603

24. Korb-Savoldelli V, Gillaizeau F, Pouchot J, Lenain E, Postel-Vinay $\mathrm{N}$, Plouin PF, et al. Validation of a French version of the 8-item Morisky medication adherence scale in hypertensive adults. J Clin Hypertens (Greenwich). 2012 Jul;14(7):429-34. PMID:22747615

25. Alhewiti A. Adherence to long-term therapies and beliefs about medications. Int J Family Med. 2014;2014:479596. PMID:24688792

26. Rattray J, Jones MC. Essential elements of questionnaire design and development. J Clin Nurs. 2007 Feb;16(2):234-43. PMID:17239058

27. Pallant J. SPSS Survival manual: a step by step guide to data analysis using SPSS. 4th ed. Crows Nest, New South Wales, Australia: Allen and Unwin; 2011.

28. Eisinga R, Grotenhuis Mt, Pelzer B. The reliability of a two-item scale: Pearson, Cronbach, or Spearman-Brown? Int J Public Health. 2013 Aug;58(4):637-42. PMID:23089674

29. American Diabetes Association. Executive summary: Standards of medical care in diabetes-2014. Diabetes Care. 2014;37 Suppl. 1:S5-13. PMID:24357214

30. Fritz CO, Morris PE, Richler JJ. Effect size estimates: current use, calculations, and interpretation. J Exp Psychol Gen. 2012 Feb;141(1):2-18. PMID:21823805

31. Mackinnon A. A spreadsheet for the calculation of comprehensive statistics for the assessment of diagnostic tests and interrater agreement. Comput Biol Med. 2000 May;30(3):127-34. PMID:10758228

32. Sakthong P, Chabunthom R, Charoenvisuthiwongs R. Psychometric properties of the Thai version of the 8-item Morisky Medication Adherence Scale in patients with type 2 diabetes. Ann Pharmacother. 2009 May;43(5):950-7. PMID:19366872

33. Briggs SR, Cheek JM. The role of factor analysis in the development and evaluation of personality scales. J Pers. 1986;54(1):106-48.

34. Rutledge T, Loh C. Effect sizes and statistical testing in the determination of clinical significance in behavioral medicine research. Ann Behav Med. 2004 Apr;27(2):138-45. PMID:15026298

35. Kadiki OA, Roaed RBM. Epidemiological and clinical patterns of diabetes mellitus in Benghazi, Libyan Arab Jamahiriya. East Mediterr Health J. 1999 Jan;5(1):6-13. PMID:10793775 